\title{
O DIREITO FINANCEIRO PRECISA SER LEVADO A SÉRIO, E 2015 COMEÇOU MAL
}

Coluna publicada em 10.2.2015:<http://www.conjur.com.br/2015-fev-10/ contas-vista-direito-financeiro-levado-serio-2015-comecou-mal $>$

O ano de 2015 não começou nada bem para o Direito Financeiro. Não só para o Direito Financeiro, mas para as finanças públicas de forma geral. A bem da verdade, o ano de 2014 já terminou muito mal.

O final do ano passado foi marcado, na esfera federal, pelas "maquiagens contábeis" que ficaram bastante conhecidas, incluindo as "pedaladas fiscais" e outros truques que nos deram um verdadeiro curso de "contabilidade criativa" e, apesar deles, as contas não fecharam no final do ano, obrigando o governo a tomar outras medidas tão ou mais lamentáveis quanto. E nada impediu que o ano terminasse com o registro do primeiro déficit nas contas desde 1997. ${ }^{2}$ Para piorar as coisas, a "contabilidade criativa" se mostrou contagiosa e já contaminou as estatais, com a Petrobras divulgando seu balanço com enorme atraso e sem incluir os prejuízos com a corrupção. ${ }^{3}$

O destaque coube para a alteração da LDO de 2014 (Lei 12.919/2013) no apagar das luzes, pois previa um superávit primário que se verificou inalcançável e, para evitar o descumprimento da lei, o "jeitinho" foi alterá-la, acabando com o superávit. ${ }^{4}$ Para conseguir aprovar a alteração na lei, o governo federal produziu

1 Atenção, caro leitor: pedalar faz mal à saúde!, nesta edição, p. 391-394.

2 Governo registra o primeiro déficit nas contas desde 1997, manchete da Folha de S.Paulo de 30 de janeiro de 2015; Contas públicas fecham 2014 com rombo inédito de R \$ 32,5 bilhôes. Folha de S.Paulo, 31 de janeiro de 2015.

3 Petrobras divulga balanço sem incluir perdas por corrupção, Exame.com, 28 de janeiro de 2015.

4 Acabar com a meta de superávit é irresponsabilidade fiscal, nesta edição, p. 395-400 e O que esperar em 2015 para o cumprimento das metas fiscais? de André Carvalho e Gabriel Lochagin, publicada em 27 de dezembro de 2014 no ConJur. 
uma das mais inacreditáveis normas já vistas. O Decreto 8.367, de 28 de novembro de 2014, "regulamentou" a inaceitável prática de troca de favores da liberação de recursos de emendas parlamentares pela aprovação da alteração na referida LDO, oficializando a "chantagem" para pressionar o Poder Legislativo - uma verdadeira "cereja no bolo" para as barbeiragens jurídicas em matéria orçamentária.

Já a LDO de 2015 (Lei 13.080), apesar de ter sido encaminhada em 15 de abril, para ser aprovada até o final de junho, só foi aprovada em 2 de janeiro de 2015, mais de seis meses após a data estabelecida na Constituição - um recorde histórico. E, ao que tudo indica, sem a adequada deliberação, pois aprovada em votação-relâmpago! Nunca antes na história desse país a LDO federal foi publicada com tanto atraso.

Começamos o ano de 2015 sem orçamento. E sem grandes expectativas de que seja aprovado em breve. O que, pelo que se vê, está se tornando uma constante. ${ }^{6}$ E neste ano, mesmo sem o orçamento ter sido aprovado, já foi feito o "contingenciamento preventivo" 7 por meio do Decreto 8.389, de 7 de janeiro de 2015, reduzindo a possibilidade de gastos que haviam sido prévia e provisoriamente autorizados cinco dias antes pela LDO 2015!!!

Um escárnio.

Difícil saber, a essa altura, o que poderá ser feito para surpreender, pois a impressão é que todos os limites da improvisação e desconsideração total pelo ordenamento jurídico em matéria financeira foram ultrapassados.

Vivemos um descalabro fiscal, na bem lançada expressão de Celso Ming, ${ }^{8}$ e que, como se vê, não é só fiscal, mas também, e principalmente, jurídico.

Correta a percepção de José Marcos Domingues expressa recentemente: estamos em uma verdadeira guerra contra o Direito Financeiro, que resulta em incerteza financeira e insegurança jurídica.

É preocupante notar que, neste ano de 2015, há várias medidas importantes a serem tomadas no âmbito do Direito Financeiro, e esperamos não sejam contaminadas pelos maus exemplos que estão se sucedendo.

5 Congresso aprova a LDO de 2015 em votação relâmpago. O Estado de S.Paulo, 17 de dezembro de 2014.

6 E o ano começa sem a aprovação do orçamento federal, nesta edição, p. 169-172.

7 Sobre esse assunto, leia Hora é de apertar o cinto e contingenciar gastos, nesta edição, p. 227-230.

8 Descalabro fiscal. O Estado de S.Paulo, 30 de janeiro de 2015.

9 Falsidade orçamentária mostra falta de planejamento, publicada em 7 de fevereiro de 2015, no ConJur. 
A começar pela aprovação dos planos plurianuais no âmbito federal e estadual, que deverão ser apresentados para debate no Poder Legislativo no segundo semestre e aprovados até o final do ano, definindo o rumo desses entes federados para os próximos quatro anos.

Ainda no aspecto do planejamento, não se pode esquecer que estados e municípios terão até o próximo dia 25 de junho para elaborar seus próprios planos de educação, em cumprimento ao disposto no art. $8^{\circ}$ do Plano Nacional de Educação - PNE (Lei 13.005, de 25 de junho de 2014). Na mesma data deverá ser aprovada a Lei de Responsabilidade Educacional (PNE, Anexo, Estratégia 20.11).

$\mathrm{E}$ os tribunais devem apresentar e adequar os respectivos planejamentos estratégicos até o próximo dia 31 de março, em cumprimento à Resolução CNJ 198, de $1^{\circ}$ de julho de 2014, artigo 16, com a previsão das estratégias e metas para 2020, o que é fundamental para uma gestão eficiente de todo o sistema de Justiça. ${ }^{10}$

Aliás, em matéria de planejamento, oportuno reparar mais uma "pérola" para usar a expressão de editorial recente da Folha de S.Paulo ${ }^{11}$ - produzida no tema, quando o Prefeito de São Paulo, vendo que não vai cumprir metas previstas no Programa de Metas da Prefeitura de São Paulo (que, registre-se, são elaboradas por ele mesmo, pois veiculadas por Decreto) ${ }_{1}^{12}$ declarou que "o que você faz é deslizar o planejamento para a frente. Você vai deslizando as medidas tomadas". ${ }^{13}$

O "planejamento deslizante" integra o rol das modernas técnicas de planejamento orçamentário por meio do qual se prevê uma atualização periódica (em geral anual) dos planos de médio ou longo prazos, de modo a suavizar e tornar previsíveis as necessárias atualizações e ajustes no planejamento, conferindo maior previsibilidade e segurança jurídica ao sistema. Está contemplado em nossa legislação por meio dos anexos de metas e riscos fiscais das leis de diretrizes orçamentárias. É um instrumento previsto no Direito Financeiro que nada tem a ver com a postergação do cumprimento das metas, pois visa dar segurança jurídica ao sistema de planejamento, e não o contrário.

A postergação das metas seria mais bem definida como um "planejamento escorregante" (cuidado para não cair!). Se a contabilidade pode ser criativa, por que não o Direito Financeiro? Fica a sugestão para esse neologismo a ser incluído nos próximos manuais de Direito Financeiro...

10 Poder Judiciário: 2014 é o ano do planejamento estratégico, nesta edição, p. 145-150.

11 Deslizamento na saúde, publicado em 26 de janeiro de 2015, no ConJur.

12 <http://planejasampa.prefeitura.sp.gov.br/metas/>.

13 Haddad já admite "deslizar" metas anunciadas para depois de 2016. Folha de S.Paulo, 25 de dezembro de 2014. 
Imprescindível levar a sério o planejamento, para o qual esta coluna já chamou a atenção por várias vezes, ${ }^{14}$ pois a falta de planejamento está prestes a nos deixar sem água ${ }^{15}$ e luz. "A falta de visão e planejamento de longo prazo é o problema grave a ser enfrentado pelo Brasil", e as crises atuais revelam que o "hábito de pensar e planejar o futuro precisa ser mais demandado dos governantes e fazer parte da reforma educacional do país", como bem colocou Henrique Meirelles recentemente. ${ }^{17}$

Mas não é só.

No final deste ano vence mais uma vez o prazo de vigência da DRU - desvinculação de receitas da União, conforme prevê o artigo 76 do Ato das Disposições Transitórias da Constituição. Aliás, ressalte-se, trata-se de artigo inserido nas disposições "transitórias" da Constituição em 1994, pela Emenda Constitucional de Revisão 1, inicialmente com a denominação de Fundo Social de Emergência. Vejam só. Vários anos após ter sido promulgada a Constituição, um dispositivo é incluído no Ato das Disposições Transitórias, cuja função é regular provisoriamente alguns temas e, desde então, vem sendo reiteradamente renovado, por sucessivas emendas constitucionais. Não há como reconhecer seriedade em medidas como essa. Sem contar que a DRU tem permitido a realocação de recursos de áreas prioritárias como saúde e educação para outras, nem tão prioritárias assim. Perpetuar sua reedição é fato para se lamentar.

O orçamento impositivo deve voltar ao centro das atenções, após ter sido objeto de intensa discussão ano passado ${ }^{18}$ e, sem que a votação da Proposta de Emenda Constitucional que o instituía tivesse sido concluída, foi "provisoriamente" contemplado na LDO de 2014. Agora, o recém-eleito presidente da Câmara dos Deputados promete retomar o debate, ${ }^{19}$ deixando uma esperança para dar mais seriedade à lei orçamentária.

Já escrevi, e volto a repetir, que o "Direito Financeiro tem sido pródigo em exemplos de afronta à Constituição e ao ordenamento jurídico como um todo", ${ }^{20} \mathrm{e}$ esse Governo está se superando ao produzir tantos exemplos.

14 Veja, entre outros textos, Planejamento municipal precisa ser levado a sério, nesta edição, p. 135-138.

15 Desafios federativos precisam ser vencidos para superar a falta d'água, nesta edição, p. 29-34.

16 Esquizofrenia no planejamento da infraestrutura aumenta os gastos, de Fernando Scaff, publicada em 27 de janeiro de 2015, no ConJur.

17 O país do futuro. Folha de S.Paulo, $1^{\circ}$ de fevereiro de 2015.

18 Orçamento impositivo é avanço para a administração, nesta edição, 231-234.

19 Vou por para votar o Orçamento impositivo, diz Cunha. O Estado de S.Paulo, 3 de fevereiro de 2015, p. A4.

20 E o ano começa sem a aprovação do orçamento federal, nesta edição, p. 169-172. 
O Direito precisa ser levado a sério, adaptando e tomando emprestada a feliz expressão de Dworkin e, nesse quesito, o Direito Financeiro deve merecer especial atenção, pois tem sido muito maltratado, como se pode notar.

Mas, como dizem, o ano só começa depois do Carnaval.

Sendo assim, é melhor tirar as fantasias do armário, decorar o samba-enredo da escola favorita e cair na folia, esperando que 2015 não traga mais surpresas negativas para o Direito Financeiro. Melhor rir para não chorar, e renovar as esperanças de que, ao começar para valer, 2015 mude as expectativas! 
